\title{
T-lymphocyte $K_{v} 1.3$ channel activation triggers the NLRP3 inflammasome signaling pathway in hypertensive patients
}

\author{
JIAN ZHU ${ }^{1}$, YAN YANG ${ }^{2}$, SI-GAN HU ${ }^{1}$, QIU-BING ZHANG ${ }^{3}$, JIE YU $^{3}$ and YUAN-MING ZHANG ${ }^{3}$ \\ Departments of ${ }^{1}$ Cardiovasology and ${ }^{2}$ Medical Oncology, The First Affiliated Hospital of Bengbu Medical College, \\ Bengbu, Anhui 233004; ${ }^{3}$ Heart Center, The First Affiliated Hospital of Xinjiang Medical University, \\ Urumqi, Xinjiang 830054, P.R. China
}

Received January 27, 2016; Accepted March 3, 2017

DOI: $10.3892 / \mathrm{etm} .2017 .4490$

\begin{abstract}
The aim of the current study was to investigate the correlation between voltage-gated potassium $1.3\left(\mathrm{~K}_{\mathrm{v}} 1.3\right)$ channel of peripheral blood T-lymphocytes and the NLR family pyrin domain containing 3 (NLRP3) inflammasome pathway in hypertensive patients. Peripheral blood samples from the hypertensive Kazakh patients $(n=30)$ and healthy Kazakh subjects $(n=30)$ were collected. The T lymphocytes and serum were separated, and the state of $\mathrm{K}_{\mathrm{v}} 1.3$ channels was detected using the patch-clamp technique. Reverse transcription-quantitative polymerase chain reaction and western blot analyses were used to detect the mRNA and protein expression levels of key molecules [NLRP3, caspase-1 and interleuking (IL)- $\beta$ ] in the lymphocyte NLRP3 inflammasome pathway, while serum IL-1 $\beta$ content was measured by ELISA assay. The results demonstrated no statistical difference in the subject baseline data between the two groups. While more significantly activated $\mathrm{K}_{\mathrm{v}} 1.3$ channels were identified in the peripheral blood T-lymphocytes of the hypertension group compared to the normotension group, the mRNA and protein expression levels of NLRP3, caspase- 1 and IL-1 $\beta$ were elevated and their peripheral serum interleukin-1 $\beta$ levels were significantly increased. After inhibiting the $\mathrm{K}_{\mathrm{v}} 1.3$ channels using the classic potassium channel blocker, these indicators were all decreased significantly. The results indicate that the NLRP3 inflammasome pathway of peripheral blood T-lymphocytes in hypertensive Kazakh patients is activated, which may be correlated with the opening of the $\mathrm{K}_{\mathrm{v}} 1.3$ channel.
\end{abstract}

Correspondence to: Dr Yuan-Ming Zhang, Heart Center, The First Affiliated Hospital of Xinjiang Medical University, 137 South Hill Road, Urumqi, Xinjiang 830054, P.R. China

E-mail: dryuanmingzhang@163.com

Key words: hypertension, T-lymphocyte, $\mathrm{K}_{\mathrm{v}} 1.3$ channels, NLRP3, caspase-1, interleukin-1 $\beta$

\section{Introduction}

Essential hypertension (EH) is a progressive cardiovascular syndrome caused by multiple factors and its pathogeneses is still being investigated. Epidemiological investigation indicated that the prevalence of hypertensive Kazakh patients in Xinjiang is significantly higher compared with those of the other nationalities in the same region, while their awareness, treatment and control rates were significantly lower (1). Recently, researchers have proposed that $\mathrm{EH}$ is a chronic low-grade inflammatory disease (2-4). The activation of T-lymphocytes, important participants in the human immune system, is closely correlated with the occurrence and development of EH $(5,6)$. There are two potassium channels on the T-lymphocyte membrane: The voltage-gated $\mathrm{K}^{+}$channel $1.3\left(\mathrm{~K}_{\mathrm{v}} 1.3\right)$ and the calcium-activated $\mathrm{K}^{+}$channel. The $\mathrm{K}_{\mathrm{v}} 1.3$ channel serves a vital role in T-lymphocyte activation (7-9). Our previous study has demonstrated that the $\mathrm{K}_{\mathrm{v}} 1.3$ channel of peripheral T-lymphocytes in hypertensive Kazakh patients in Xinjiang serves a role in the onset of hypertension (10); however, the specific underlying mechanisms were unclear. There is evidence that NLR family pyrin domain containing 3 (NLRP3) (also named cryopyrin, CIAS1 or NALP3) participates in the formation of inflammasome, which is involved in the onset of hypertension along with its main downstream product, interleukin-1 $\beta$ (IL-1 $\beta$ ) (11-13). Declined intracellular $\mathrm{K}^{+}$level is considered to be one of the main mechanisms of NLRP3 inflammasome activation $(14,15)$. Therefore, it can be inferred that the T-lymphocyte $\mathrm{K}_{\mathrm{v}} 1.3$ channel may be involved in the regulation of hypertension through activation of the NLRP3 inflammasome pathway (Fig. 1).

The present study aimed to further verify the expression levels of molecules associated with the NLRP3 pathway in the peripheral blood T-lymphocytes of hypertensive Kazakh patients. In addition, the correlation of these molecules with the $\mathrm{K}_{\mathrm{v}} 1.3$ channel was explored, attempting to provide novel experimental evidence and theoretical basis for the inflammatory mechanisms of hypertension.

\section{Materials and methods}

Subjects. A total of 30 hypertensive (defined as systolic blood pressure $\geq 140 \mathrm{mmHg}$ and/or diastolic blood pressure 
$\geq 90 \mathrm{mmHg}$ ) Kazakh patients, who were not receiving antihypertensive drug treatment and were first admitted to the Cardiology Center of the First Affiliated Hospital of Xinjiang Medical University (Urumqi, China) between June and December 2014, were randomly enrolled into the present study as the hypertension group. The mean age of the hypertensive patients was $57.4 \pm 5.6$ years and their mean blood pressure was $170.1 \pm 8.5 / 103.5 \pm 7.6 \mathrm{mmHg}$. In addition, 30 healthy Kazakh subjects, with a mean age of $55.8 \pm 4.8$ years and mean blood pressure of $122.2 \pm 6.6 / 71.1 \pm 6.4 \mathrm{mmHg}$, were also enrolled during the same period and served as the control group. The male to female ratio was 1:1 in each group. The 1999 World Health Organization International Society of Hypertension Guidelines for the Management of Hypertension (16) were used as the diagnostic criteria for hypertension in the present study. Based on laboratory results and clinical examinations, any patients with secondary hypertension, acute cardiovascular disease, atherosclerosis, rheumatic heart disease, congenital heart disease, acute and chronic infections, systemic autoimmune diseases, diabetes and vital organ failure were excluded from the study. All protocols were approved by the Ethics Committee of the First Affiliated Hospital of Xinjiang Medical University and all patients provided informed consent.

Reagents. Human lymphocyte separation medium,4-aminopyridine (4-AP), N-2-hydroxyethylpiperazine-N'-2'-ethanesulfonic acid (HEPES), and $\mathrm{K}^{+}$asparate were obtained from Sigma-Aldrich (St. Louis, MO, USA). The TRIzol reagent, 5-bromo-4-chloro-3-indolyl phosphate/nitroblue tetrazolium (BCIP/NBT) solution and the reverse transcription kit (catalog no. K1622) were purchased from Thermo Fisher Scientific, Inc. (Waltham, MA, USA). The reverse transcription-quantitative polymerase chain reaction (RT-qPCR) kit (catalog no. 204054) was obtained from Qiagen (Hilden, Germany). In addition, the anti-NLRP3 (catalog no. 13158S; 1:1,000), anti-caspase-1 (catalog no. 3866S; 1:1,000), anti-IL-1ß (catalog no. 31202S; 1:1,000) and anti-GAPDH (catalog no. 2118S; 1:1,000) rabbit monoclonal antibodies, as well as the anti-rabbit IgG, alkaline phosphatase-linked secondary antibody (catalog no. 7054S, 1:2,000), were from Cell Signaling Technology, Inc. (Beverly, MA, USA). The IL-1 $\beta$ ELISA kit (catalog no. BMS224/2) was obtained from eBioscience (San Diego, CA, USA), while the FITC-labeled anti-CD3 antibody (catalog no. 340571) and recombinant human IL-2 (rIL-2) were from BD Biosciences (San Jose, CA, USA). The RPMI 1640 culture medium and fetal bovine serum were from GE Healthcare (Chicago, IL, USA). The other patch-clamp associated reagents were obtained from Amresco (Solon, OH, USA).

Sample collection. Approximately $12 \mathrm{ml}$ peripheral venous blood was collected from each subject. All samples were then treated with heparin for anticoagulation and divided into two portions of 2 and $10 \mathrm{ml}$ each. The $10 \mathrm{ml}$ sample was separated by the lymphocyte separation medium to isolate mononuclear cells, which were then treated by negative magnetic-activated cell sorting to obtain the T-lymphocyte suspension. The acquired cells were then labeled by the FITC-CD3 monoclonal antibody and measured by flow cytometry sorting, which proved that $>95 \%$ of cells were T-lymphocytes. Next, the mRNA and proteins of T-lymphocytes were extracted and

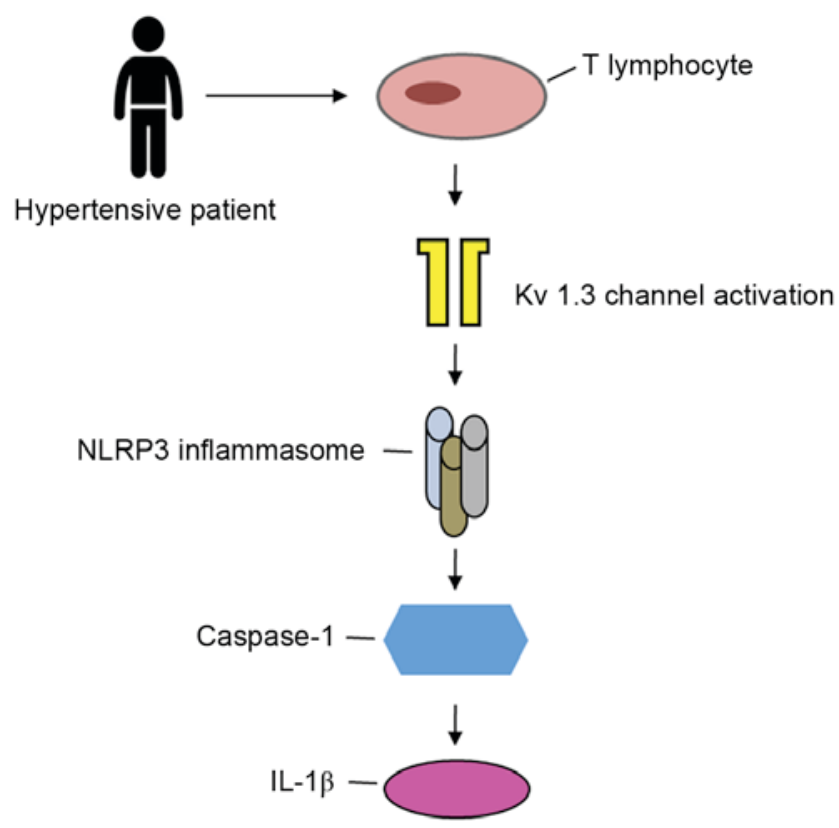

Figure 1. A proposed model for T-lymphocyte $\mathrm{K}_{\mathrm{v}} 1.3$ channel activation to trigger the NLRP3 inflammasome signaling pathway in hypertensive patients. $\mathrm{K}_{\mathrm{v}} 1.3$, voltage-gated $\mathrm{K}^{+}$channel 1.3; IL-1 $\beta$, interleukin-1 $\beta$; NLRP3, NLR family pyrin domain containing 3 .

stored at $-80^{\circ} \mathrm{C}$ in the refrigerator. T-lymphocytes from the hypertension group were equally divided into two portions, with one portion prepared for mRNA and protein extraction and the other for the drug intervention experiment. The remaining $2 \mathrm{ml}$ of the peripheral venous blood samples was centrifuged at $1,000 \mathrm{x} \mathrm{g}$ for $5 \mathrm{~min}$ to collect the supernatant serum, which was then stored in the refrigerator at $-80^{\circ} \mathrm{C}$.

In vitro proliferation of T-lymphocytes from the hypertension group. After a $24-\mathrm{h}$ proliferation period in the RPMI 1640 culture medium containing $10 \%$ fetal bovine serum and $50 \mathrm{U} / \mathrm{ml} \mathrm{rIL-2,} \mathrm{the} \mathrm{T-lymphocytes} \mathrm{were} \mathrm{harvested} \mathrm{and}$ equally divided into two portions. One portion was cultured in medium containing 4-AP (4-AP group, with a final 4-AP concentration of $3 \mathrm{mmol} / \mathrm{l}$ ) and the other in medium without 4-AP (blank group). Subsequent to separate culturing for $48 \mathrm{~h}$, the T-lymphocytes were collected for mRNA, protein extraction and patch clamp recording, while the cell suspensions were harvested and stored in a $-80^{\circ} \mathrm{C}$ refrigerator.

Whole-cell patch-clamp recording. Patch-clamp current recording for each sample (2-4 cells) was completed within $4 \mathrm{~h}$ under $20-24^{\circ} \mathrm{C}$. The separated T-lymphocytes were placed into the extracellular fluid, which contained $150 \mathrm{mmol} / \mathrm{l}$ $\mathrm{NaCl}, 4.5 \mathrm{mmol} / 1 \mathrm{KCl}, 1.0 \mathrm{mmol} / \mathrm{l} \mathrm{CaCl}_{2}, 1.0 \mathrm{mmol} / 1 \mathrm{MgCl}_{2}$ and $10 \mathrm{mmol} / \mathrm{l}$ HEPES, whose $\mathrm{pH}$ was adjusted to 7.35 using $\mathrm{NaOH}$. The microelectrodes were fabricated by a two-step microelectrode puller; then, they were filled with a suitable pipette solution, which contained $150 \mathrm{mmol} / 1 \mathrm{KCl}, 1.0 \mathrm{mmol} / \mathrm{l}$ $\mathrm{CaCl}_{2}, 1.0 \mathrm{mmol} / 1 \mathrm{MgCl}_{2}, 10 \mathrm{mmol} / \mathrm{l}$ HEPES and $10 \mathrm{mmol} / \mathrm{l}$ EDTA, and was adjusted to a $\mathrm{pH}$ of 7.2 using $\mathrm{NaOH}$. The resistance of the microelectrode ranged between 3 and $6 \mathrm{M} \Omega$. The T-lymphocyte suspension was placed under the microscope using a perfusion slot worktable. After $30 \mathrm{~min}$ of standing, 
Table I. Primer sequences for human NLRP3, caspase-1, IL-1 $\beta$ and $\beta$-actin.

\begin{tabular}{|c|c|c|c|}
\hline Gene & Sequence $\left(5^{\prime}-3^{\prime}\right)$ & Annealing temperature $\left({ }^{\circ} \mathrm{C}\right)$ & Product size (bp) \\
\hline NLRP3 & $\begin{array}{l}\text { F: AAGCACCTGTTGTGCAATCTGAAG } \\
\text { R: GGGAATGGCTGGTGCTCAATAC }\end{array}$ & 60 & 103 \\
\hline Caspase-1 & $\begin{array}{l}\text { F: GCCTGTTCCTGTGATGTGGA } \\
\text { R: TTCACTTCCTGCCCACAGAC }\end{array}$ & 55 & 175 \\
\hline IL-1 $\beta$ & $\begin{array}{l}\text { F: AGTGGCAATGAGGATGACTTGT } \\
\text { R: TGTAGTGGTGGTCGGAGATTC }\end{array}$ & 55 & 127 \\
\hline$\beta$-actin & $\begin{array}{l}\text { F: CTAAGTCATAGTCCGCCTAGAAGCA } \\
\text { R: TGGCACCCAGCACAATGAA }\end{array}$ & 55 & 186 \\
\hline
\end{tabular}

IL-1 $\beta$, interleukin-1 $\beta$; NLRP3, NLR family pyrin domain containing 3.

when the lymphocytes were fully adhered, the whole-cell patch-clamp recording was initiated under room temperature. The EPC10 amplifier (HEKA Elektronik, Lambrecht, Germany) was adopted to record the potassium current of the individual lymphocytes under the voltage clamp mode. The outer and inner diameters of the recording electrode were 1.5 and $0.8 \mathrm{~mm}$, respectively. The tip diameter of the recording electrode was $\sim 1 \mu \mathrm{m}$ and the electrode resistance was $\sim 5 \mathrm{M} \Omega$, while the electrodes were filled with a pipette solution. Subsequent to contacting the cells with a micromanipulator, negative pressure was applied to create a $>1 \mathrm{G} \Omega$ condition for sealing, with a general sealing resistance of 1-20 M $\Omega$. After compensating the electrode capacitance, transient high negative pressure or strong electric stimulation was applied to break the cell membrane and form a whole-cell patch clamp. The membrane current was filtered by a $10 \mathrm{kHz}(-3 \mathrm{~dB})$ low frequency filter, and the bioelectric signals were recorded using a PC. After achieving the whole-cell recording mode, the clamping voltage was $-80 \mathrm{mV}$. Following the administration of depolarization-impulse stimulation from $-80 \mathrm{mV}$ to $+80 \mathrm{mV}$ for $200 \mathrm{msec}$, the potassium current was measured. Subsequently, T-lymphocytes were perfused by 4-AP with a final concentration of $3 \mathrm{mmol} / \mathrm{l}$ in order to observe the current changes. The cutoff frequency of the signal was $10 \mathrm{kHz}$, and the signals were sampled and stored.

RNA extraction and $R T-q P C R$. The total RNA of peripheral blood T-lymphocytes was extracted with TRIzol reagent, and the $A_{260} / A_{280}$ absorbance was found to be between 1.8 and 2.0. Next, $1 \mu \mathrm{g}$ RNA was used for reverse transcription with the following reaction conditions: $42^{\circ} \mathrm{C}$ for $60 \mathrm{~min}$ and $70^{\circ} \mathrm{C}$ for $5 \mathrm{~min}$. The acquired cDNA was used in the sequential PCR reaction. The reaction system of quantitative fluorescent PCR was as follows: $10 \mu \mathrm{l}$ SYBR Green PCR Master Mix (2X; Qiagen), $2 \mu \mathrm{l} \mathrm{cDNA}$ template, $0.5 \mu \mathrm{l}(10 \mu \mathrm{mol} / \mathrm{l})$ forward/reverse primer

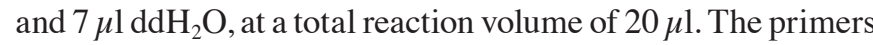
for NLRP3, caspase-1 and IL-1 $\beta$ were synthesized by Sangon Biotech Co., Ltd. (Shanghai, China), and human $\beta$-actin was used as the internal control. Specific primer fragments and annealing temperatures are listed in Table I. PCR was initiated at $95^{\circ} \mathrm{C}$ for $3 \mathrm{~min}$ followed by 40 cycles of $95^{\circ} \mathrm{C}$ for $30 \mathrm{sec}$, annealing for $30 \mathrm{sec}$ (see Table I for annealing temperatures), and $72^{\circ} \mathrm{C}$ for $30 \mathrm{sec}$, with the final cycle extended to $72^{\circ} \mathrm{C}$ for
5 min, followed by termination at $4^{\circ} \mathrm{C}$. When the reactions ended, the PCR products were placed on $2 \%$ agarose gels and analyzed by the $2^{-\Delta \Delta \mathrm{Cq}}$ method to obtain the mRNA expression.

Western blot analysis. Total proteins of T-lymphocytes were extracted for the measurement of the protein concentration of NLRP3, caspase-1 and IL-1 $\beta$. Briefly, $20 \mu \mathrm{g}$ protein and adequate loading buffer were added per well, denatured in a $95^{\circ} \mathrm{C}$ waterbath and analyzed by $12 \%$ sodium dodecyl sulphate-polyacrylamide gel electrophoresis. Subsequent to electrophoresis, the proteins were electronically transferred onto a polyvinylidene difluoride filter membrane, blocked by skimmed milk for $1 \mathrm{~h}$ at room temperature and co-incubated overnight with the appropriate rabbit anti-human primary antibody $(1: 1,000)$ on a shaker at $4^{\circ} \mathrm{C}$. After rinsing, the membrane was co-incubated for $2 \mathrm{~h}$ with the AP-labeled goat anti-rabbit secondary antibody $(1: 2,000)$ on a shaker at room temperature. Following additional rinsing, the membrane was treated with $5 \mathrm{ml} \mathrm{BCIP/NBT}$ solution according to the manufacturer's instructions. The Quantity One 1-D analysis software version 4.6.3 (Bio-Rad Laboratories, Inc., Hercules, CA, USA) was used to analyze the protein ladders. Protein expression levels were normalized to those of internal controls (GAPDH).

Detection of $I L-1 \beta$ content in the serum and cell culture medium supernatants. For ELISA detection, the manufacturer's instructions were strictly followed using the original reagents from the IL-1 $\beta$ ELISA kit. IL- $1 \beta$ levels were evaluated in samples from the normotension vs. hypertension groups (serum), and the 4-AP treated vs. untreated groups (supernatants). Triplicated wells were set for the samples and standard reference. The final absorbance values of proteins were read by a microplate reader at $450 \mathrm{~nm}$, while the means were used to calculate the IL- $1 \beta$ contents of the corresponding samples based on the established standard curves.

Statistical analysis. The SPSS version 17.0 software (SPSS, Inc., Chicago, IL, USA) was used for statistical analysis. Numerical data are expressed as the means \pm standard deviation, while their pairwise comparison was analyzed by Student's $t$ test, with $\mathrm{P}<0.05$ indicating statistically significant differences. 
Table II. Baseline data of both the normotension and hypertension groups.

\begin{tabular}{lcrr}
\hline Variables & Normotension $(\mathrm{n}=30)$ & Hypertension $(\mathrm{n}=30)$ & P-value \\
\hline Age (years) & $55.8 \pm 4.8$ & $57.4 \pm 5.6$ & 0.220 \\
Hypertension history (\%) & 40.0 & 43.3 & $>0.999$ \\
Smoking history (\%) & 40.0 & 36.7 & $>0.999$ \\
Drinking history (\%) & 46.7 & 50.0 & $>0.999$ \\
BMI $\left(\mathrm{kg} / \mathrm{m}^{2}\right)$ & $25.6 \pm 1.2$ & $26.1 \pm 1.6$ & 0.610 \\
Fasting glucose (mmol/l) & $5.1 \pm 0.6$ & $5.3 \pm 0.4$ & 0.330 \\
CRP $(\mathrm{mg} / \mathrm{l})$ & $9.2 \pm 1.5$ & $9.8 \pm 1.2$ & 0.124 \\
TG $(\mathrm{mmol} / \mathrm{l})$ & $1.8 \pm 0.3$ & $1.9 \pm 0.5$ & 0.725 \\
HDL $(\mathrm{mmol} / \mathrm{l})$ & $1.4 \pm 0.3$ & $1.3 \pm 0.2$ & 0.455 \\
LDL $(\mathrm{mmol} / \mathrm{l})$ & $3.3 \pm 0.8$ & $3.5 \pm 0.8$ & 0.289
\end{tabular}

Numerical data are presented as the mean \pm standard deviation. BMI, body mass index; CRP, C-reaction protein; TG, triglycerides; HDL, high density lipoprotein cholesterol; LDL, low-density lipoprotein cholesterol.

\section{Results}

Comparison of baseline data between the hypertension and normotension groups. No significant differences were identified in the age, hypertension history, smoking or drinking history, body mass index, fasting glucose, C-reaction protein, triglycerides, high density lipoprotein cholesterol or low-density lipoprotein cholesterol levels between the two groups ( $\mathrm{P}>0.05)$, indicating comparability (Table II).

Current density of the T-lymphocyte $K_{v} 1.3$ channel. The acquired outward current of the T-lymphocyte $\mathrm{K}_{\mathrm{v}} 1.3$ channel after administering stimulation according to the aforementioned plan was similar to that reported previously (17). The current-voltage curve of the $\mathrm{K}_{\mathrm{v}} 1.3$ channel indicated that the current was voltage-dependent, which was consistent with the current characteristics of the $\mathrm{K}_{\mathrm{v}} 1.3$ channel (Fig. 2A). Compared with the normotension group, the activation degree of the $\mathrm{K}_{\mathrm{v}} 1.3$ channel in the peripheral blood T-lymphocytes of patients from the hypertension group was significantly higher $(179 \pm 51$ vs. $280 \pm 74 \mathrm{pA} / \mathrm{pF}$, respectively; $\mathrm{P}<0.05$; Fig. $2 \mathrm{~B}$ and $\mathrm{C}$ ).

mRNA and protein expression levels of NLRP3, caspase-1 and $I L-1 \beta$ in the T-lymphocytes. Compared with the normotension group, the mRNA and protein relative expression levels of NLRP3, caspase-1 and IL-1 $\beta$ in the hypertension group were significantly higher as determined by RT-qPCR and western blot analysis (Fig. 3A and B). In addition, the serum IL- $\beta$ content in the peripheral blood of hypertensive patients measured by ELISA was also significantly higher in comparison with the levels in the normotension group (Fig. 3C).

Impact of 4-AP upon the $K_{v} 1.3$ channel current. According to the previously described $\mathrm{K}_{\mathrm{v}} 1.3$ channel stimulation procedures, upon perfusion with $4-\mathrm{AP}$, the $\mathrm{K}_{\mathrm{v}} 1.3$ channel current of T-lymphocytes from the hypertensive subjects recorded by the patch clamp method was significantly lower in the 4-AP treated group in comparison with that in the blank group (Fig. 4). This observation confirmed that exposure to 4-AP with a concentration of $3 \mathrm{mmol} / \mathrm{l}$ was able to inhibit the current activity of T-lymphocyte $\mathrm{K}_{\mathrm{v}} 1.3$.

Expression changes in key molecules in the NLRP3 signaling pathway of T-lymphocytes subsequent to $K_{v} 1.3$ channel blockage. In comparison with the blank group, after blocking the T-lymphocyte $\mathrm{K}_{\mathrm{v}} 1.3$ channel from the hypertensive subjects with 4-AP, the mRNA and protein expression levels of NLRP3, caspase-1 and IL-1 $\beta$ declined significantly as detected by RT-qPCR and western blot analysis (Fig. 5A and B). Furthermore, the IL-1 $\beta$ content in the culture supernatant of T-lymphocytes from the hypertensive subjects also decreased significantly as determined using ELISA (Fig. 5C).

\section{Discussion}

Hypertension is a chronic low-grade inflammatory process characterized by activation of the lymphatic and mononuclear systems $(5-6,18)$. The activation and function of lymphocytes is closely correlated with the ionic channels distributed on their surface. The $\mathrm{K}_{\mathrm{v}} 1.3$ channel is mainly involved in the activation process of T-lymphocytes. After activation and opening, the $\mathrm{K}_{\mathrm{v}} 1.3$ channel promotes the influx of extracellular $\mathrm{Ca}^{2+}$, indirectly regulating the division, proliferation, apoptosis and function of T-lymphocytes (19). Due to the dependence of this membrane potential-calcium signal, it is predicated that $\mathrm{K}_{\mathrm{v}} 1.3$ channel blockers may inhibit the activation and proliferation of T-lymphocytes and result in immune suppression. This prediction has been proven in various in vivo and in vitro experiments (20,21). A previous study by the current authors in a spontaneously hypertensive rat (SHR) model indicated that the mRNA and protein levels of the $\mathrm{K}_{\mathrm{v}} 1.3$ channel structural protein (Gene ID: 29731) in high-grade SHRs (16-week old) were significantly higher compared with those of the low-grade SHRs (4-week old) (22). The patch-clamp records also revealed that the current density of the T-lymphocyte $\mathrm{K}_{\mathrm{v}} 1.3$ channel was significantly higher in the high-grade SHRs compared with low-grade SHRs (23). Furthermore, this channel could be effectively blocked by 4-AP in a significantly concentration-dependent manner $(23,24)$. Sequentially, it was 

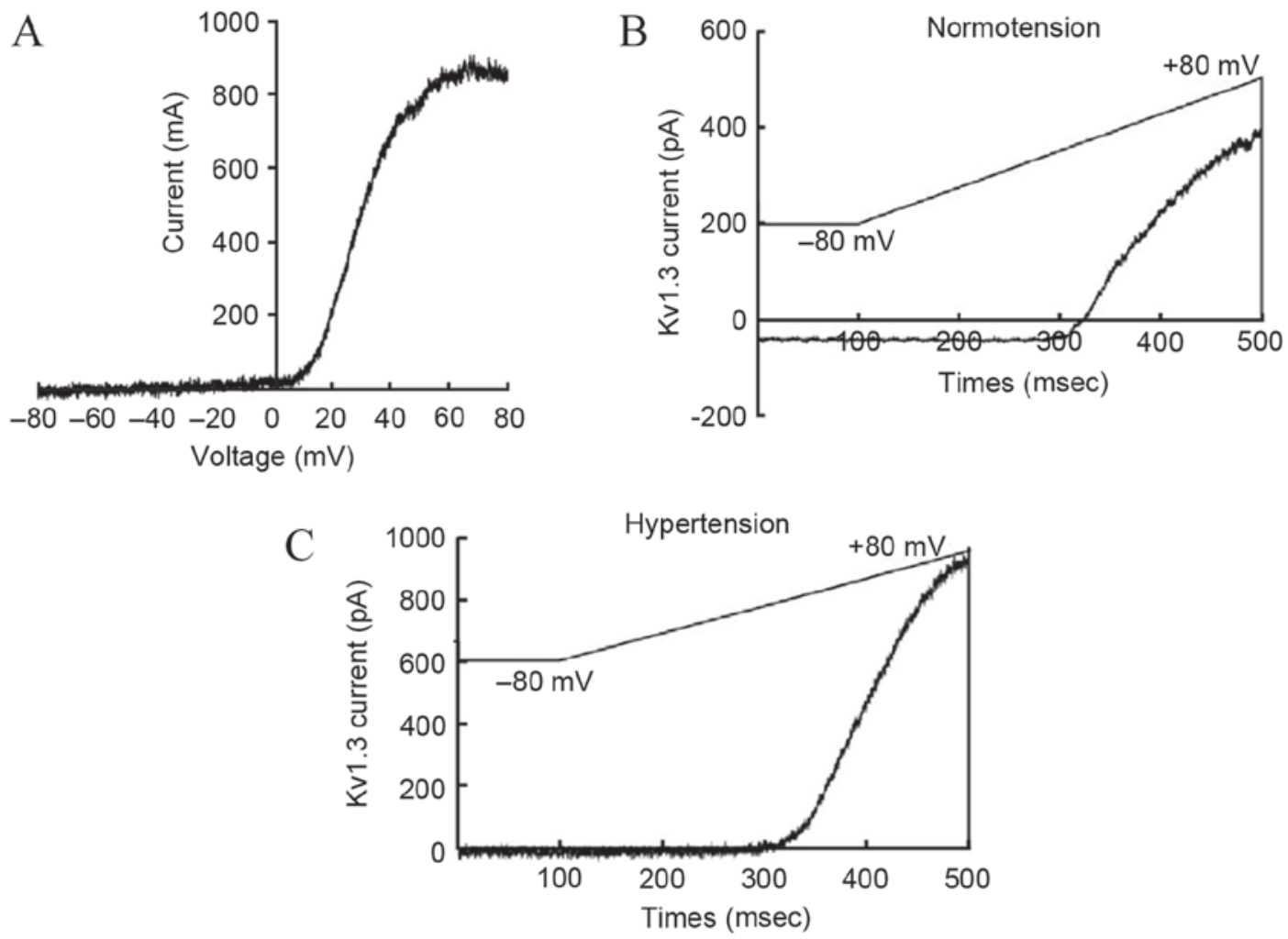

Figure 2. Comparison of peripheral blood T-lymphocyte current densities between the normotension and hypertension groups. (A) Current-voltage curve of the $\mathrm{K}_{\mathrm{v}} 1.3$ channel was constructed based on the records of currents and corresponding voltages. Outward current curves of the (B) normotension and (C) hypertension groups were recorded following the $\mathrm{K}_{\mathrm{v}} 1.3$ channel electric stimulation regimen. Compared with the normotension group, the peripheral blood T-lymphocyte current density of the hypertension group was significantly increased. $\mathrm{K}_{\mathrm{v}} 1.3$, voltage-gated $\mathrm{K}^{+}$channel 1.3 .

further observed that the current density of the T-lymphocyte $\mathrm{K}_{\mathrm{v}} 1.3$ channel in hypertensive Kazakh patients was significantly higher compared with that of the normotension group (10). These previous findings $(10,22-24)$ indicate that the activation of T-lymphocytes and the $\mathrm{K}_{\mathrm{v}} 1.3$ channel on its membrane are closely correlated with hypertension; however, the specific mechanisms and downstream signaling pathways remain unknown.

Inflammasome, a vital component of the innate immune system, is an intracellular multiprotein complex consisting of the NLRs family and caspase-1 (25). NLRP3 is the crucial support of the protein complex, while apoptosis-associated speck-like protein containing CARD is the bridge between NLRP3 and pro-caspase-1 (26). The NLRP3 inflammasome is widely expressed in dendritic cells and monocyte-macrophages. When activated, NLRP3 shears pro-caspase-1 into its activated form, caspase-1, which is capable of shearing the precursor form of the IL-1 superfamily members, resulting in maturity and release of the IL-1 superfamily members (26). In this way, it actively participates in immune defense or injury, and leads to vascular remodeling and blood pressure increase. Recent research demonstrated that NLRP3 inflammasome may become a potential biomarker and therapeutic target for early hypertension (27). Therefore, it can be inferred that the NLRP3 inflammasome pathway of peripheral blood T-lymphocytes in hypertensive Kazakh patients in Xinjiang may also be activated, while the NLRP3 inflammasome may be an effective downstream molecule of the $\mathrm{K}_{\mathrm{v}} 1.3$ channel, involved in hypertension development.
In the present study, the expression levels of key molecules (NLRP3, caspase-1 and IL-1 $\beta$ ) in the NLRP3 inflammasome pathway of peripheral blood T-lymphocytes were measured, while the association between the T-lymphocyte $\mathrm{K}_{\mathrm{v}} 1.3$ channel and the NLRP3 inflammasome pathway was also analyzed. The results indicated that peripheral blood T-lymphocyte $\mathrm{K}_{\mathrm{v}} 1.3$ channel in hypertensive Kazakh patients was activated, which confirmed our previous findings $(23,24)$. Since the $\mathrm{K}_{\mathrm{v}} 1.3$ channel can influence the cell membrane potential and activate the calcium signaling pathway, it serves an important role during the activation of T-lymphocytes (17). Therefore, the current results indicate that T-lymphocytes in the selected hypertensive population were activated to a certain extent. Studies have demonstrated that activated T-lymphocytes, induced by Angiotensin II (Ang II), served an important role in the occurrence of hypertension and endothelial dysfunction (5). Schiffrin (6) also documented the influential role of T-lymphocytes during hypertension and vascular remodeling. The study also pointed out that the transcription factor Foxp3 expressed by T-lymphocytes, including the T helper cells (Th1, Th2 and Th17) and suppressor T cells (including the regulatory T cells), was closely correlated with the production of Ang II (6). Therefore, T-lymphocytes served a critical role during the onset and progression of EH. These T-lymphocytes and functional states of $\mathrm{K}_{\mathrm{v}} 1.3$ channels influenced the activity of the NLRP3 inflammasome pathway. The sequential results of the present study revealed that the mRNA and protein expression levels of key molecules in the NLRP3 inflammasome signal pathway (namely NLRP3, caspase-1, and IL-1 $\beta$ ) were 
A

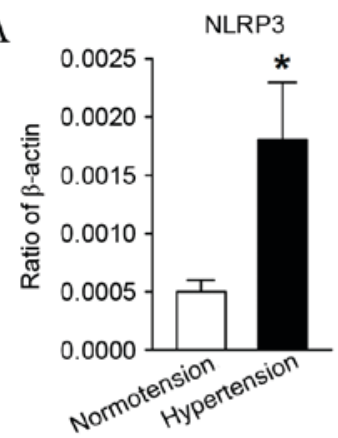

$\mathrm{B} \underset{\mathrm{GAPPH}}{\mathrm{NLRP}}=110 \mathrm{kDa}$

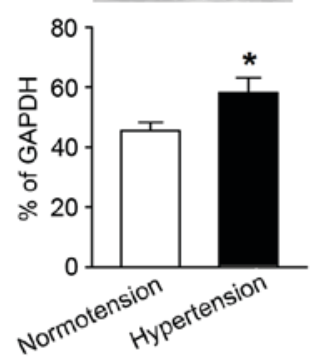

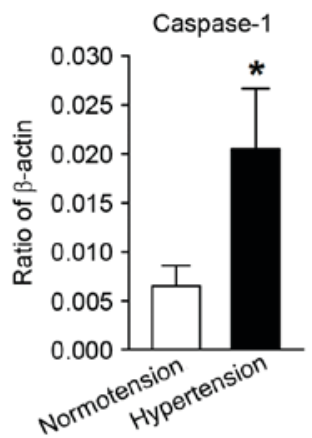
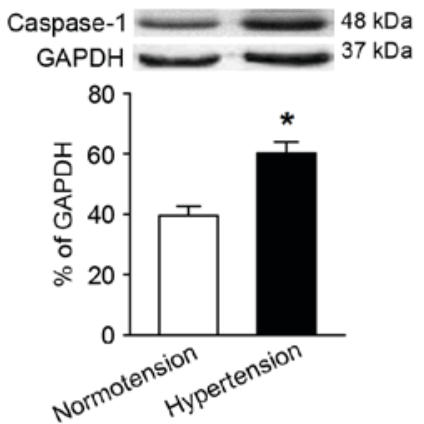

$\mathrm{C}$

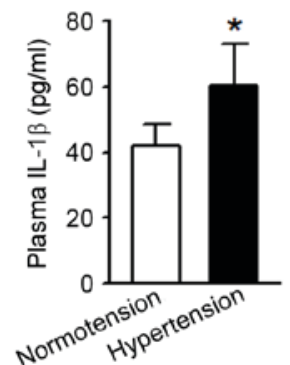

IL-1 $1 \beta$
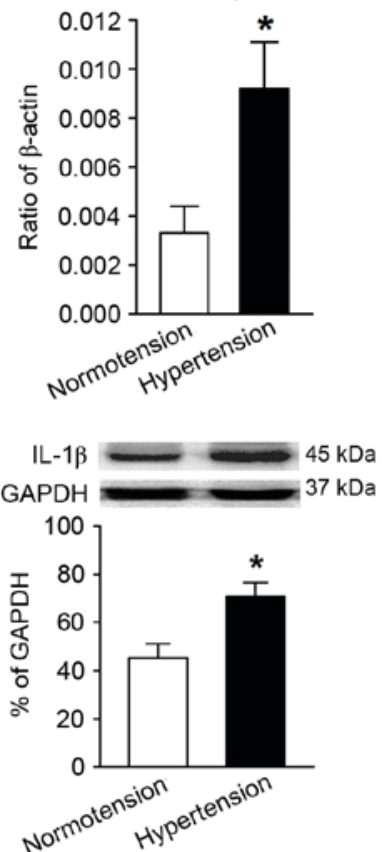

Figure 3. Comparison of the expression levels of molecules associated with the NLRP3 inflammasome pathway and its downstream product, IL-1 $\beta$, between the normotension and hypertension groups. (A) Reverse transcription-quantitative polymerase chain reaction and (B) western blot analysis indicated the relative mRNA and protein expression levels, respectively, of NLRP3, caspase-1 and IL-1 $\beta$. These levels were significantly higher in the hypertension group compared with the normotension group. (C) ELISA results confirmed that the peripheral serum IL-1 $\beta$ content was significantly higher in the hypertension group. ${ }^{\mathrm{P}}<0.05$ vs. Normotension. IL-1 $\beta$, interleukin-1 $\beta$; NLRP3, NLR family pyrin domain containing 3.
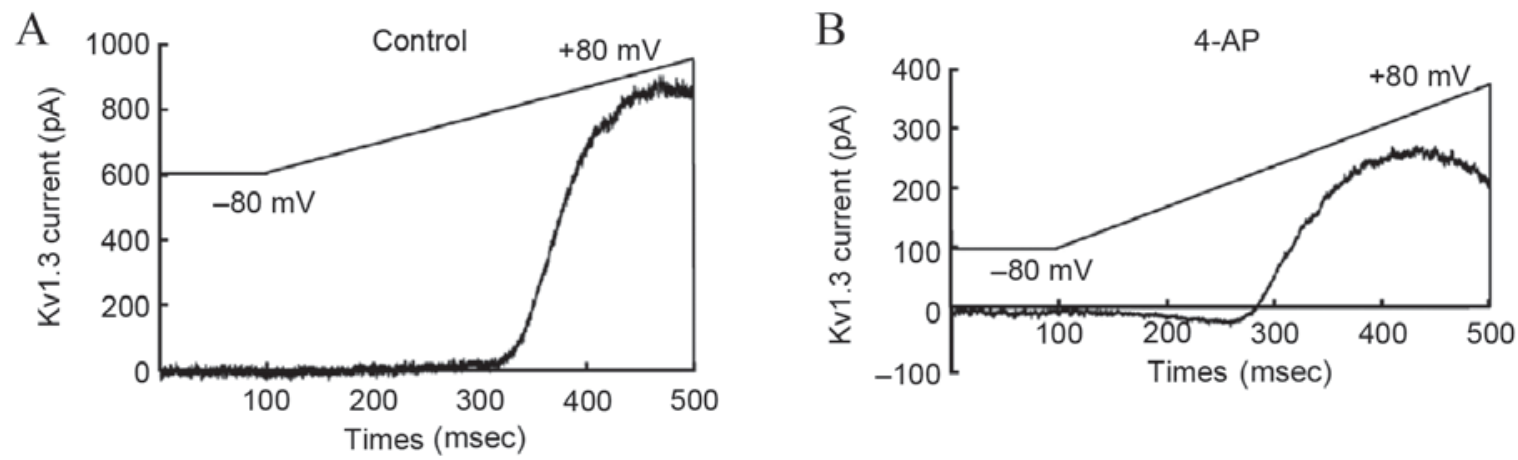

Figure 4. Current density changes of peripheral blood T-lymphocyte $\mathrm{K}_{\mathrm{v}} 1.3$ channel from the hypertensive subjects in the (A) control and (B) following 4-AP intervention. Subsequent to perfusion by the 4-AP at a final concentration of $3 \mathrm{mmol} / 1$, the current density of the T-lymphocyte membrane $\mathrm{K}_{\mathrm{v}} 1.3 \mathrm{channel}$ in the 4-AP perfusion group was significantly lower, compared with the blank control group. 4-AP, 4-aminopyridine; $\mathrm{K}_{\mathrm{v}} 1.3$, voltage-gated $\mathrm{K}^{+}$channel 1.3 .

significantly higher in the hypertension group when compared with the healthy normotension group. For the mechanisms underlying NLRP3 inflammasome activation, multiple endogenous and exogenous stimuli, such as $\mathrm{K}^{+}$efflux, lysosomal instability and increased levels of intracellular reactive oxygen, have been demonstrated to activate the NLRP3 inflammasome pathway (28). Among these, the low intracellular levels of $\mathrm{K}^{+}$ are considered the final common mechanism through which the NLRP3 inflammasome activates caspase-1 $(14,29)$. The results of the current study support the aforementioned observations. Therefore, it is suggested that the activation of potassium channels is the trigger for activation of the NLRP3 inflammasome 
A

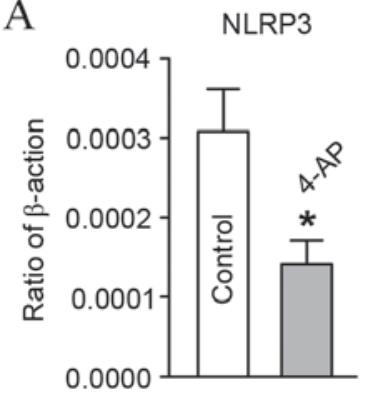

B
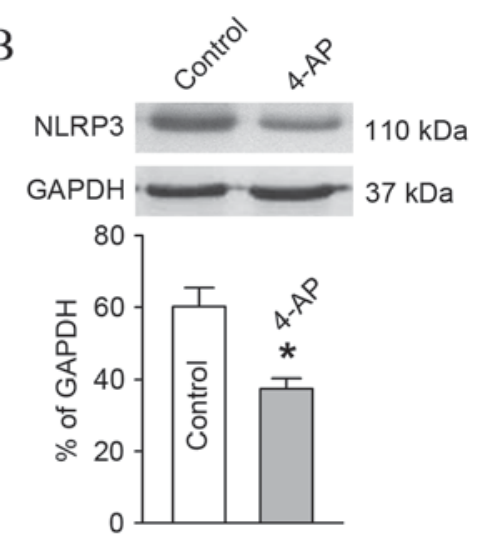
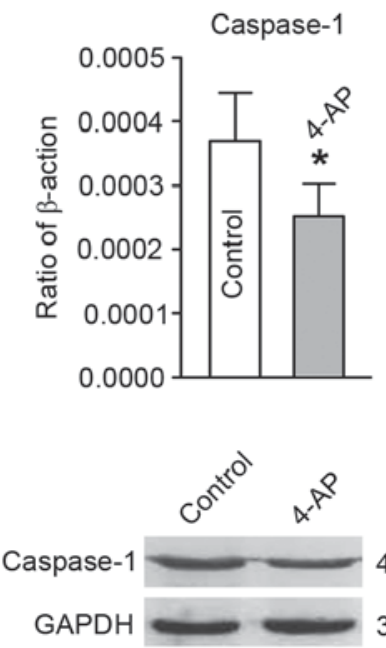

$48 \mathrm{kDa}$
$37 \mathrm{kDa}$

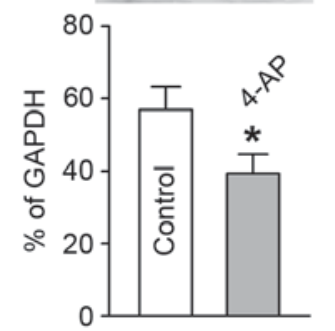

C

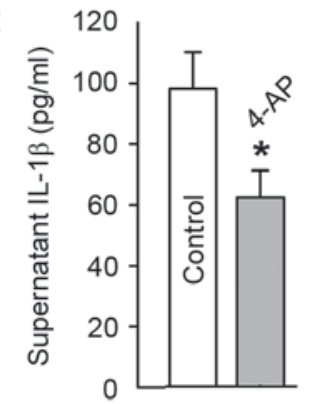

IL-1 $\beta$

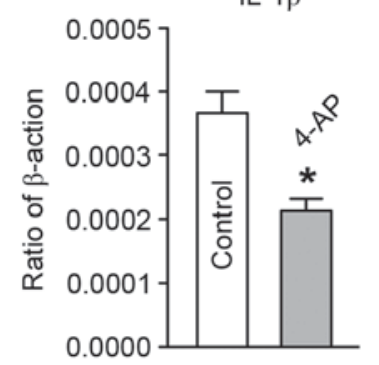

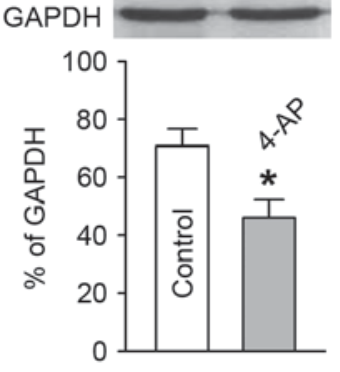
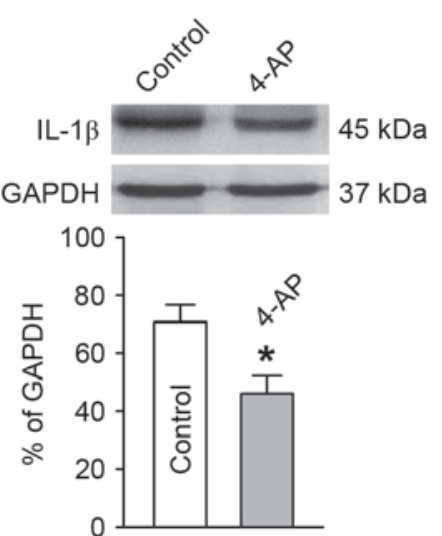

Figure 5. Alterations in expression levels of molecules associated with the NLRP3 inflammasome pathway and its downstream product, IL-1 $\beta$, after blocking the T-lymphocyte $\mathrm{K}_{\mathrm{v}} 1.3$ channel in the hypertensive subjects. T-lymphocytes were incubated in the culture medium with or without 4 -AP for 48 h. (A) Reverse transcription-quantitative polymerase chain reaction and (B) western blot analysis showed the relative mRNA and protein expression levels, respectively, of NLRP3, caspase-1 and IL-1 $\beta$. These expression levels were significantly lower in the 4-AP group compared with the blank control group. (C) ELISA results indicated that the IL-1 $\beta$ content in the culture medium supernatant was significantly lower in the 4 -AP group. * $\mathrm{P}<0.05$ vs. Control. 4 -AP, 4 -aminopyridine; $\mathrm{K}_{\mathrm{v}} 1.3$, voltage-gated $\mathrm{K}^{+}$channel 1.3; IL-1 $\beta$, interleukin-1 $\beta$; NLRP3, NLR family pyrin domain containing 3 .

pathway in the present study, since additional in vitro drug intervention experiments have verified that blockage of the $\mathrm{K}_{\mathrm{v}} 1.3$ channel with the aim to reduce the $\mathrm{K}^{+}$efflux may inhibit the activation of the inflammasome pathway and the release of its downstream product IL-1 $\beta$. It should be stated here that the classic potassium channel blocker 4-AP was found to effectively block the $\mathrm{K}_{\mathrm{v}} 1.3$ channel at a concentration of $3 \mathrm{mmol} / \mathrm{l}$, which is consistent with previous reports $(30,31)$. The NLRP3 inflammasome pathway inactivation caused by potassium channel blockage is of great importance, since IL-1 $\beta$, the key downstream molecule of the NLRP3 inflammasome pathway, is closely correlated with the occurrence of hypertension. Studies have demonstrated that IL-1 $\beta$ can lead to changes in the vascular endothelial cell (VEC) morphology and intracellular skeletal structure, resulting in VEC functional damage and a massive release of cytokines, such as endothelin 1, which may have significant biological effects, including an increase in blood pressure $(32,33)$. Furthermore, IL-1 $\beta$ can also upregulate the expression of type 1 Ang receptor II (11), directly impacting blood pressure regulation. IL-1 $\beta$ is also considered to be one of the predictors of blood pressure problems in the elderly (34).

In conclusion, the findings of the present study revealed that the $\mathrm{K}_{\mathrm{v}} 1.3$ channel was activated, while the expression levels of molecules associated with the NLRP3 inflammasome pathway and its key downstream product were increased. Blocking the $\mathrm{K}_{\mathrm{v}} 1.3$ channel could result in inactivation of this pathway, indicating that the NLRP3 inflammasome may be the downstream effector molecule of the $\mathrm{K}_{\mathrm{v}} 1.3$ channel. However, due to the limited sample size, this is only a preliminary exploration of the correlation between the $\mathrm{K}_{\mathrm{v}} 1.3$ channel on the membrane of peripheral blood T-lymphocytes and the NLRP3 inflammasome pathway in hypertensive Kazakh patients in the Xinjiang region, China. In the future, studies with expanded 
population size comparing the Han and Kazakh populations from the same region, and animal experiments to verify the paradigm are required for a deeper understanding of the association between the T-lymphocyte NLRP3 inflammasome pathway activation and the T-lymphocyte $\mathrm{K}_{\mathrm{v}} 1.3$ channel. Such studies would provide additional experimental evidence and theoretical basis for the pathogenesis of $\mathrm{EH}$.

\section{Acknowledgements}

The present study was supported by a grant from the National Natural Science Foundation of China (no. 81160039).

\section{References}

1. Liu F, Ma YT, Yang YN, Xie X, Li XM, Huang Y, Ma X, Chen BD, Gao X and Du L: Current status of primary hypertension in Xinjiang: An epidemiological study of Han, Uygur and Hazakh populations. Zhonghua Yi Xue Za Zhi 90: 3259-3263, 2010 (In Chinese).

2. Harrison DG, Guzik TJ, Lob HE, Madhur MS, Marvar PJ, Thabet SR, Vinh A and Weyand CM: Inflammation, immunity, and hypertension. Hypertension 57: 132-140, 2011.

3. Montecucco F, Pende A, Quercioli A and Mach F: Inflammation in the pathophysiology of essential hypertension. J Nephrol 24: 23-34, 2011.

4. Dinh QN, Drummond GR, Sobey CG and Chrissobolis S: Roles of inflammation, oxidative stress, and vascular dysfunction in hypertension. Biomed Res Int 2014: 406960, 2014.

5. Guzik TJ, Hoch NE, Brown KA, McCann LA, Rahman A, Dikalov S, Goronzy J, Weyand C and Harrison DG: Role of the $\mathrm{T}$ cell in the genesis of angiotensin II induced hypertension and vascular dysfunction. J Exp Med 204: 2449-2460, 2007.

6. Schiffrin EL: T lymphocytes: A role in hypertension? Curr Opin Nephrol Hypertens 19: 181-186, 2010.

7. Hu L, Pennington M, Jiang Q, Whartenby KA and Calabresi PA: Characterization of the functional properties of the voltage-gated potassium channel Kv1.3 in human CD4+ T lymphocytes. J Immunol 179: 4563-4570, 2007.

8. Wulff H, Calabresi PA, Allie R, Yun S, Pennington M, Beeton C and Chandy KG: The voltage-gated $\mathrm{Kv1} .3 \mathrm{~K}(+)$ channel in effector memory T cells as new target for MS. J Clin Invest 111: 1703-1713, 2003.

9. Schmitz A, Sankaranarayanan A, Azam P, Schmidt-Lassen K, Homerick D, Hänsel W and Wulff H: Design of PAP-1, a selective small molecule Kv1.3 blocker, for the suppression of effector memory $\mathrm{T}$ cells in autoimmune diseases. Mol Pharmacol 68 : $1254-1270,2005$

10. Zhang QB, Zhang YM, Cheng LF, Yuan QY, Zhang GM, Liang P and Gou F: Voltage-dependent potassium channel and calcium-activated potassium channel current changes of peripheral blood T-lymphocytes from hypertensive patients in Xinjiang Kazakh. Zhonghua Xin Xue Guan Bing Za Zhi 41: 1020-1024, 2013 (In Chinese).

11. Sasamura H, Nakazato Y, Hayashida T, Kitamura Y, Hayashi M and Saruta T: Regulation of vascular type 1 angiotensin receptors by cytokines. Hypertension 30: 35-41, 1997.

12. Dorffel Y, Lätsch C, Stuhlmüller B, Schreiber S, Scholze S, Burmester GR and Scholze J: Preactivated peripheral blood monocytes in patients with essential hypertension. Hypertension 34: $113-117,1999$

13. Omi T, Kumada M, Kamesaki T, Okuda H, Munkhtulga L, Yanagisawa Y, Utsumi N, Gotoh T, Hata A, Soma M, et al: An intronic variable number of tandem repeat polymorphisms of the cold-induced autoinflammatory syndrome 1 (CIAS1) gene modifies gene expression and is associated with essential hypertension. Eur J Hum Genet 14: 1295-1305, 2006.

14. Munoz-Planillo R, Kuffa P, Martínez-Colon G, Smith BL, Rajendiran TM and Núñez G: $\mathrm{K}^{+}$efflux is the common trigger of NLRP3 inflammasome activation by bacterial toxins and particulate matter. Immunity 38: 1142-1153, 2013.
15. Marina-García N, Franchi L, Kim YG, Miller D, McDonald C, Boons GJ and Núñez G: Pannexin-1-mediated intracellular delivery of muramyl dipeptide induces caspase-1 activation via cryopyrin/NLRP3 independently of Nod2. J Immunol 180: 4050-4057, 2008

16. Chalmers J: The 1999 WHO-ISH guidelines for the management of hypertension. Med J Aust 171: 458-459, 1999.

17. Panyi G, Possani LD, Rodríguez de laVega RC, Gáspár R and Varga Z: K+ channel blockers: Novel tools to inhibit T cell activation leading to specific immunosuppression. Curr Pharm Des 12: 2199-2220, 2006.

18. Harrison DG, Marvar PJ and Titze JM: Vascular inflammatory cells in hypertension. Front Physiol 3: 128, 2012.

19. Lewis RS: Calcium signaling mechanisms in T lymphocytes. Annu Rev Immunol 19: 497-521, 2001

20. Damjanovich S, Gáspár R and Panyi G: An alternative to conventional immunosuppression: Small-molecule inhibitors of Kv1.3 channels. Mol Interv 4: 250-254, 2004.

21. Leonard RJ, Garcia ML, Slaughter RS and Reuben JP: Selective blockers of voltage-gated $\mathrm{K}+$ channels depolarize human $\mathrm{T}$ lymphocytes: Mechanism of the antiproliferative effect of charybdotoxin. Proc Natl Acad Sci USA 89: 10094-10098, 1992.

22. Luo J, Zhang YM, Ma KT, Si JQ and Liang P: Difference in the expression of Kv channel in lymphocytes between spontaneously hypertensive rats and Wistar rats. Sheng Li Xue Bao 62: 382-386, 2010 (In Chinese).

23. Luo J, Ma KT, Zhang YM, Si JQ, Liang P and Li J: Effects of telmisartan on 4-Aminopyridine-sensitive voltage dependant potassium channel of lymphocyte derived from spontaneously hypertensive rat. Zhonghua Xin Xue Guan Bing Za Zhi 38: 751-754, 2010 (In Chinese).

24. Zhang Q, Zhang Y, Cheng L, Yuan Q, Zhang G and Gou F: Effects of telmisartan on IKCa1 potassium channel after T-lymphocyte activation and proliferation in peripheral blood of hypertensive patients in Xinjiang Kazakh. Zhonghua Yi Xue Za Zhi 94: 182-186, 2014 (In Chinese).

25. Koizumi Y, Toma C, Higa N, Nohara T, Nakasone N and Suzuki T: Inflammasome activation via intracellular NLRs triggered by bacterial infection. Cell Microbiol 14: 149-154, 2012

26. Schroder K and Tschopp J: The inflammasomes. Cell 140: 821-832, 2010.

27. De Miguel C, Rudemiller NP, Abais JM and Mattson DL: Inflammation and hypertension: New understandings and potential therapeutic targets. Curr Hypertens Rep 17: 507, 2015.

28. Kawaguchi M, Takahashi M, Hata T, Kashima Y, Usui F, Morimoto H, Izawa A, Takahashi Y, Masumoto J, Koyama J, et al: Inflammasome activation of cardiac fibroblasts is essential for myocardial ischemia/reperfusion injury. Circulation 123: 594-604, 2011.

29. Pétrilli V, Papin S, Dostert C, Mayor A, Martinon F and Tschopp J: Activation of the NALP3 inflammasome is triggered by low intracellular potassium concentration. Cell Death Differ 14: 1583-1589, 2007.

30. Leung G, Sun W, Brookes S, Smith D and Shi R: Potassium channel blocker, 4-aminopyridine-3-methanol, restores axonal conduction in spinal cord of an animal model of multiple sclerosis. Exp Neurol 227: 232-235, 2011.

31. Panyi G, Varga Z and Gáspár R: Ion channels and lymphocyte activation. Immunol Lett 92: 55-66, 2004.

32. Ziesche R, Petkov V, Williams J, Zakeri SM, Mosgöller W, Knöfler M and Block LH: Lipopolysaccharide and interleukin 1 augment the effects of hypoxia and inflammation in human pulmonary arterial tissue. Proc Natl Acad Sci USA 93: 12478-12483, 1996

33. Nemati F, Rahbar-Roshandel N, Hosseini F, Mahmoudian M and Shafiei M: Anti-inflammatory effects of anti-hypertensive agents: Influence on interleukin- $1 \beta$ secretion by peripheral blood polymorphonuclear leukocytes from patients with essential hypertension. Clin Exp Hypertens 33: 66-76, 2011.

34. Barbieri M,Ferrucci L, Corsi AM, Macchi C,Lauretani F, Bonafè M, Olivieri F, Giovagnetti S, Franceschi C and Paolisso G: Is chronic inflammation a determinant of blood pressure in the elderly? Am J Hypertens 16: 537-543, 2003. 